\title{
INSALUBRIDADE: AINDA UM DESAFIO
}

\author{
Diogo Pupo Nogueira(1) \\ Jorge da Rocha Gomes (2)
}

RESUMO: Após um rápido retrospecto histórico sobre a criação do adicional de insalu. bridade, é demonstrada a situaçáo desse acréscimo salarial no Brasil. Demonstra-se que a concessão do adicional de insalubridade é uma atitude imoral e desumana que consiste, em última análise, na compra da vida e da saúde dos trabalhadores. Concluiu. se pela necessidade de se substituir esse adicional por medidas que obriguem os empregadores a propiciar aos seus trabalhadores um ambiente de trabalho que não ofereça riscos à saúde destes.

\begin{abstract}
After a brief revision of the origins of risk-money, the Brazilian situation is described. It is made clear that to pay to a worker an adition percentage of his salary due to the fact that he works in a place where his health or even his life is endangered, is an atitude both imoral and against the basic rights of humanity. It is concluded that such payment must stop and that a very rigorous legislation should be created as to force employers to offer to their workers conditions of work which will not affect health them.
\end{abstract}

O advento da Revolução Industrial teve, como uma de suas conseqüências, a exposição dos trabalhadores a riscos até então desconhecidos. Dessa forma, à medida que surgiam os riscos mecânicos, físicos, químicos e biológicos em diferentes locais de trabalho, também surgiam doenças até então desconhecidas, as doenças ocupacionais, muitas das quais de elevada gravidade. Tornava-se, pois, absolutamente necessária a adoção de medidas preventivas que evitassem tais agravos à saúde dos trabalhadores.

Enquanto a higiene, a segurança e a medicina do trabalho lentamente começavam a se preocupar com essas medidas preventivas, uma forma aparentemente mais rápida de realizá-las na prática foi o pagamento de um adicional de insalubridade, ou seja, o pagamento aos trabalhadores expostos a tais agentes de uma quantia adicional ao seu salário. Os que propugnavam por esse pagamento raciocinavam que o pagamento do adicional constituiria uma espécie de multa para os empregadores, levando-os a adotar medidas técnicas de proteção à saúde dos trabalhadores.

Tal multa, cujo montante reverteria para o próprio trabalhador que sofria as conseqüências das condições inadequadas de trabalho, deveria resultar em melhor alimentação, melhores condições de habitação e de lazer, ou seja, uma qualidade de vida que o tornaria mais

(1) Chefe do Departamento de Saúde Ambiental da Faculdade de Saúde Pública - USP.

12) Professor Assistente Doutor do Departamento de Saúde Ambiental da Faculdade de Saúde Pública - USP. 
apto a se defender dos agentes agressivos do seu meio de trabalho. Como se verá adiante, o adicional de insalubridade nem levou os empregadores a uma política de correção das condições insalubres e não melhorou em nada as condições de vida dos trabalhadores.

O pagamento desse adicional mostrou-se, na Europa, totalmente ineficaz. Estudos posteriores de toxicologia ocupacional evidenciaram que mesmo uma dieta extremamente rica, que o adicional de insalubridade não punha ao alcance do trabalhador, não aumentava a resistência dos trabalhadores frente às doenças ocupacionais; por outro lado, os empregadores frente à alternativa de pagar o adicional ou tornar salubres os locais de trabalho, escolhiam a primeira alternativa por ser menos onerosa e mais facilmente inserível no preço da mercadoria produzida.

Por outro lado, uma situação de particular gravidade ocorreu, principalmente nos países em desenvolvimento, onde os baixíssimos salários levavam os trabalhadores a aceitarem trabalhos em condições insalubres para poder aumentá-los. Os empregadores, por sua vez, não tinham maior interesse em esclarecer os trabalhadores sobre os riscos a que se expunham, desobrigando-se dessa obrigação mediante o pagamento de adicional de insalubridade.

O reconhecimento de que esse adicional de insalubridade em nada contribuía para a melhoria da saúde dos trabalhadores, levou os países europeus a aboli-lo, atitude que, mais tarde, foi adotada pela indústria norte-americana. Nesse sentido, SIMONIN (1956), grande conhecedor da Saúde Ocupacional, assim afirmava:

"Pensamos que o adicional dito de insalubridade é imoral e desumano; é uma espécie de adicional do suicídio; ele encoraja os mais temerários a arriscar a saúde para aumentar seu salário; é contrário aos princípios da Medicina do Trabalho e à Declaração dos

Direitos do Homem: nenhuma consideração de ordem econômica deverá jamais compelir a um trabalho que implique o risco de comprometer a saúde de quem o realiza" (Os grifos são nossos).

A imoralidade de se pagar a um trabalhador para que ele trabaIhe em condições de risco à saúde são claras nas palavras do ilustre mestre, o que levou à abolição do adicional de insalubridade praticamente em todos os países altamente industrializados.

No Brasil, porém, as coisas correram de forma diferente. Quando foi criado o salário mínimo na década de 40, desde o início verificou-se que o valor desse salário era bastante baixo. Para complementá-lo, os legisladores, lamentavelmente, criaram o adicional de insalubridade. Assim, afirmavam estes que " quando se tratar da fixação do salário mínimo dos trabalhadores ocupados em serviços 
insalubres, poderão as Comissões de salário mínimo aumentá-lo até a metade do salário mínimo normal da região, ou subzona" Nascia, assim, 0 adicional de insalubridade, que tantos malefícios iria causar aos trabalhadores nos anos que se seguiram.

Evidentemente, o risco à saúde dos trabalhadores que o adicional de insalubridade criava recebeu o repúdio de todos os que se dedicavam à Saúde Ocupacional. Em 1974, SUSSEKIND (1974) fazia notar que " na verdade a adoção do pagamento de um adicional de insalubridade deve ser apenas tolerado como decorrência de o Estado, atendendo sobretudo aos interesses do país, ser incapaz de impedir o funcionamento de atividades insalubres" (Os grifos são nossos). Criticava-se, dessa forma, o governo federal que, por motivo estritamente econômico, tinha criado o adicional de insalubridade por crer ser muito dispendioso um programa de melhores condições de trabalho.

Também na Justiça do Trabalho, a quem competia a ordem de pagamento do adicional de insalubridade quando este era reclamado pelo empregado, algumas vozes faziam ouvir o seu protesto. Assim, CORREA (1974), juiz do Trabalho, afirmava:

"Parece-nos que a substituição dos meios capazes de proteger o empregado contra os efeitos da insalubridade por um simples pagamento adicional repugna a consciência civilizada e não se coaduna com um pais que se orgulha das tradições cristãs $e$

humanisticas de que está eivada sua história. Como diz o prof. Simonin, da França, ao pagarmos o adicional de insalubridade estamos sendo, antes de tudo desumanos e cruéis"

E ainda CORRÉA (1974) quem afirma que o pagamento do adicional ". estabelece uma fuga legal para os maus empresários, indiferentes ao desgaste físico dos seus empregados, provocado pelo agente insalutífero. "o que constitui, na verdade" um homicídio a longo prazo"

Não menos candente é a crítica de PUECH (1963) que, quando procurador da Justiça do Trabalho, assim afirmava:

"Sistema condenado pelos estudiosos - entre os quais sobrelevam os profs. Cesarino Junior e Alfredo Ruprecht - tornou cômoda

a prática, hoje em dia generalizada, de deixarem os patrões descuidadas as suas instalações industriais, esperando que, afinal, reclamem os empregados o preco fixado em lei e em troca do qual estes Ihe vendem anos de vida ou de saúde, na base de 10, 20 ou $40 \%$ de adicionais calculados sobre o salário mínimo, prática em torno da qual se arregimentam os sindicatos de trabalhadores, desta forma fazendo o 'jogo dos patrões', pois estes, quando não se 
dispõem a organizar suas fábricas conforme as normas de higiene e segurança, já demonstraram à sociedade, nestes vinte anos de adicionais, suas preferências pelo odioso processo de compra da saúde dos trabalhadores"

Não obstante as palavras de PUECH serem de 1963, nem por isso inf́luenciou patrões e trabalhadores. Estes continuam exigindo o pagamento de adicionais em lugar de exigirem boas condições de trabalho e os patrões continuam a fazer tal pagamento em lugar de tornar salubres seus locais de trabalho. Dessa forma, sabe-se perfeitamente o custo mensal da saúde e/ou vida de um trabalhador brasileiro, que é exatamente $40 \%$ de um salário mínimo.

Nos últimos anos, representantes dos trabalhadores estão modificando sua atitude frente à insalubridade, preferindo lutar por meIhores condições de trabalho do que solicitar o pagamento do adicional. Cria-se, assim, uma nova atitude de oposição à monetarização do risco, que somente poderá ser devidamente apreendida pelos trabaIhadores quando for-lhes indicados os riscos a que se expõem durante o seu trabalho e a absoluta necessidade de medidas preventivas em lugar de venda da sua saúde e da sua vida. No entanto, caso o trabaIhador não estiver bem cônscio desse posicionamento sindical, poderá estranhar por que seu sindicato não envida esforços no sentido de que ele receba o adicional; torna-se, pois, indispensável que a exemplo do que é feito em países altamente industrializados, seja feita uma cuidadosa educação do trabalhador no sentido de levá-lo a exigir dos seus empregadores condições salubres de trabalho, e não o adicional de insalubridade.

Uma nova legislação, que veio aumentar ainda mais o interesse dos trabalhadores pelo adicional de insalubridade, é a que regulamenta a aposentadoria especial. De acordo com que dispõem os artigos de 60 a 64, do Decreto no 83.080, de 24 de janeiro de 1979, que aprova o Regulamento dos Benefícios da Previdência Social, os trabalhadores que, contando com 60 contribuições mensais aos órgãos previdenciários, tenham trabalhado em determinadas atividades insalubres, terão direito a uma aposentadoria especial aos 15, 20 ou 25 anos de trabalho, conforme a atividade realizada, em lugar dos 35 anos de trabalho exigidos para os trabalhadores em geral. Em decorrência disso, aumentou muito o interesse dos trabalhadores em exercer suas atividades laborativas em ambientes insalubres, para poder aposentarse mais cedo. Desconhecendo os riscos a que se expõem ou dando a eles mínima importância, estão dispostos a continuar trabalhando, mas pondo em risco sua saúde e sua vida. Com isso, poderão alcançar a aposentadoria especial almejada, mas não poderão gozá-la por serem portadores de sérios agravos à sua saúde; em casos extremos, 
poderão não chegar nem mesmo aos 15 anos de trabalho, sendo vitimados por uma doença ocupacional antes de alcançá-los. Exemplo típico é o dos trabalhadores expostos a concentrações elevadas de poeiras contendo sílica livre; a pneumoconiose daí decorrente -- a silicose - é uma doença que, uma vez iniciada, progride inexoravelmente e, dessa forma, seus portadores não viverão suficientemente para alcançar a aposentadoria especial que tanto almejavam. Outro exemplo é o de trabalhadores expostos a níveis elevados de ruído, que se aposentarão mais cedo mas portadores de surdez profissional irremediável.

Em outros casos, trabalhadores que vinham trabalhando há muitos anos em condições insalubres, quando a insalubridade se torna conhecida através, por exemplo, de uma perícia ou de uma fiscalização, procuram afanosamente comprovar tal situação para aposentarem-se mais cedo, recusando - algumas vezes de maneira enfática que sejam adotadas medidas de neutralização ou eliminação da insalubridade para que não percam as vantagens de uma aposentadoria precoce.

Quando as condições de insalubridade não implicam em aposentadoria especial, é relativamente freqüente ver os trabalhadores se oporem à melhoria dos locais de trabalho para que não percam o adicional de insalubridade a que têm direito.

Uma só pode ser a solução desse grave problema: a substituição do princípio de pagamento do adicional de insalubridade pela adoção de medidas de higiene do trabalho que realmente possam impedir que o trabalhador apresente uma doença profissional. Essas medidas deverão ser impostas tanto pelos agentes governamentais de fiscalização como, e principalmente, pelos próprios trabalhadores. Em lugar de venderem suas vidas e saúde aos empregadores, por um preço ridiculamente baixo, devem os trabalhadores propugnar. por todos os meios possíveis, pela eliminação de todo e qualquer risco de doença profissional a que estejam expostos. Por outro lado, os empregadores que não tomarem as medidas necessárias para neutralizar ou, preferivelmente, eliminar a insalubridade existente, devem receber severas sanções. Para que possam conhecer tais riscos, devem os trabalhadores ser alertados claramente sobre a natureza destes. Esse esclarecimento deve ser prestado, primeiramente, pelas entidades operárias mas, e também, pelos próprios empregadores: é o chamado "direito de saber", que vem sendo discutido em todo o mundo e que consubstanciou-se na Recomendação no 171 (OIT 1986) e na Convenção n? 161 (OIT, 1986), da Organização Internacional do Trabalho (OIT), aprovado em 1985. Os dois documentos são bastantes claros, como se verá a seguir. 
O artigo 22 da Recomendação assim afirma:

22.1) Todo o trabalhador deveria ser informado, de maneira conveniente e adequada, dos riscos para a sua saúde que acarreta o seu trabalho, dos resultados dos exames de saúde a que tenha sido submetido e da avaliação do seu estado de saúde.

22.2) Todo o trabalhador deveria ter o direito de exigir que se corrija qualquer dado que seja errôneo ou que possa induzir a erro.

22.3) Os serviços de saúde no trabalho deveriam, além disso, assessorar individualmente os trabalhadores a respeito da sua saúde em relação ao trabalho.

Por outro lado, o artigo 13 da Convenção no 161 diz que "todos os trabalhadores deverão ser informados dos riscos que seu trabaIho apresenta para sua saúde"

Cabe ao Congresso Nacional referendar a Convenção, com o que criar-se-á para o trabalhador brasileiro o direito de saber exatamente os riscos que cada tipo de trabalho acarreta. Espera-se que, tomando conhecimento tanto por intermédio de órgãos de representação operária como pelos próprios patrões, dos riscos a que se expõem e da inutilidade de uma aposentaćoria especial quando sua saúde e mesmo sua vida estarão totalmente prejudicadas, certamente preferirão os trabalhadores exigir condições hígidas de trabalho em lugar de exigir o pagamento do adicional de insalubridade, como já ocorre nos países altamente industrializados.

Como bem afirma RIBEIRO (1965), "a supressão da insalubridade não apresenta, na quase totalidade das situações, problema insolúvel. O adiantamento técnico da Higiene do Trabalho, nos dias fresentes, permite o planejamento e efe tivação de medidas que garantam a salubridade do local de trabalho em face da grande maioria dos agentes potenciais de agressão"

Quando a insalubridade não puder ser eliminada ou, pelo menos neutralizada, outras medidas podem ser adotadas. $\dot{E}$ ainda RIBEIRO (1965) quem as enumera: " redução da duração da jornada de trabalho; a limitação, com ou sem redução da jornada de trabalho, do tempo de exposição a agentes nocivos; a proibição de horas suplementares de trabalho; as pausas intercalares lno decurso de cada período de trabalho) $e$ interperiódicas (entre um $e$ outro período de jornada); as pausas diárias (entre uma e outra jornada) e semanais. ¿ as pausas anuais (férias) obrigatórias que, além de mais longas que as usuais, poderão, segundo o caso, serem concedidas com mais fre- 
qüência (semestrais, trimestrais etc.). Está claro que nenhuma redução se efetuará no salário normal da jornada, reduzida em conseqüência a estas prescrições, e que os dias de férias serão integralmente pagos como se de jornada de trabalho fossem"

Com a adoção dessas medidas poder-se-ia proteger eficazmente a vida e a saúde dos trabalhadores.

No que tange à aposentadoria especial, poder-se-ia mantê-la em função não da insalubridade existente, mas em face de determinados tipos de trabalho que, por exigirem demasiado de um trabalhador, levam a um desgaste físico ou psíquico maior.

Ainda uma palavra sobre o adicional de insalubridade. Quando da sua criação, 6 trabalhador exposto deveria receber um acréscimo igual até $50 \%$ de um salário mínimo. Legislação posterior atribuiu três graus de insalubridade, podendo os trabalhadores a estes expostos receberem 10, 20 ou $40 \%$ de um salário mínimo. Essa gradação de adicional é totalmente empírica e nenhum dado científico a justifica. Como bem diz RIBEIRO (1965), " a não ser no caso de exposição a altas concentrações de certos agentes nocivos em que, pela agudeza da ação, as conseqüências se interpretam mais como um acidente do trabalho do que como uma doença profissional, não nos oferecem a Toxicologia e a Patologia Profissional, em que pese todo. o esforço perquiridor dos investigadores, dados seguros que permitem prever e graduar os efeitos das exposições crônicas. Dada a complexidade das variáveis envolvidas, ainda não atingimos essa perfeição em toxicologia profissional crônica. O máximo que se consegue são aproximações grosseiras do valor procurado"

Dessa forma, portanto, o adicional de insalubridade, além de imoral e desumano, ainda atenta contra todos os princípios de higiene, segurança e medicina do trabalho ao estabelecer, sem qualquer base científica, a gradação dos riscos ambientais.

E pensamento do governo federal criar um Código do Trabalho, onde se incluiriam toda a legislação trabalhista ora dispersa em vários documentos legais. Cabe, pois, nesse momento uma vigorosa campanha de esclarecimento sobre a problemática do adicional de insalubridade e, ao mesmo tempo, com exigências quanto à obrigação do empregador em propiciar aos seus trabalhadores um ambiente isento de riscos à saúde destes. Deve-se esperar que os sindicatos de trabalhadores, agora mais ativos e com maior liberdade, propugnem ardorosamente por esses dois objetivos, cuja aplicação irá garantir aos trabalhadores em geral uma vida longa e isenta de problemas de saúde. 
1 - CORREA, A.N. apud SUSSEKIND, A. et alii. Direito do trabaIho. Rio de Janeiro, Freitas Bastos, 1974.

2 - ORGANIZACION INTERNACIONAL DEL TRABAJO. Conferencia Internacional del Trabajo. Recomendación sobre los servicios de salud en el trabajo, 1985 (Recomendación 171), Ginebra, OIT 1986.

3 - ORGANIZACIÓN INTERNACIONAL DEL TRABAJO. Conferencia Internacional del Trabajo. Convenio sobre los servicios de salud en el trabajo, 1985 (Convenio 161), Ginebra, OIT, 1986.

4 - PUECH, L.R. Combate à insalubridade industrial. O Estado de S. Paulo. São Paulo, 21 de abril de 1963.

5 - RIBEIRO, B.A. Conceituação e caracterização de insalubridade e suas implicações legais. Arq. Fac. Hig. São Paulo, 19: 79-90, 1965.

6 - SIMONIN, C. Médecine du Travail. Paris, Maloine, 1956.

7 - SUSSEKIND, A. et alii. Direito do trabalho. Rio de Janeiro, Freitas Bastos, 1974.

\section{FICHA CATALOGRÁFICA}

NOGUEIRA, D. P. \& GOMES, J. R. Insalubridade: ainda um desafio. Revista da Universidade de São Paulo. São Paulo, (5) : 99-106, jun. 1987. 